three weeks the patient's parkinsonism improved somewhat but he remained disabled. Although clinical and laboratory evidence argued against neurosyphilis, a two week course of doxycycline was then given, but the patient did not improve over the next four weeks. His symptoms subsequently improved considerably on increasing doses of levodopa with carbidopa.

This man developed a severe symmetrical parkinsonian syndrome responsive to levodopa whose striking feature was its sudden onset. The only precipitant apparent in the history and from investigations was the flurbiprofen. There are reports of extrapyramidal syndromes in patients taking non-steroidal anti-inflammatory drugs ' ' but few specifically of parkinsonism. Parkinsonian symptoms have appeared in a few patients taking indomethacin (Merck Sharp and Dohme, personal communication) and been worsened by sulindac in a patient with idiopathic Parkinson's disease already receiving a levodopa and carbidopa preparation." Conversely, diflunisal improved symptoms in six patients with Parkinson's disease." Flurbiprofen has been associated with various motor disorders including ataxia (five reports), tremor (four reports), and myoclonus, akathisia, hypertonia, and extrapyramidal disorder (one report each). (Boots; Committee for the Safety of Medicines, personal communications). To these should now be added the akinetic rigid syndrome.

It is unknown how flurbiprofen mediated its effects, but they were only partially reversible. The findings in the positron emission tomography scan indicated nigrostriatal cell loss, as is seen in idiopathic Parkinson's disease, ${ }^{\circ}$ in contrast with the normal appearance seen in some patients with parkinsonism induced by neuroleptic drugs (D J Brooks, personal communication). We suspect that this patient had subclinical nigral cell loss, which rendered him susceptible to a superimposed drug effect.

1 Wood N, Pall HS, Williams AC, Dieppe C. Extrapyramidal reactions to anti-inflammatory drugs. I Neurol Neurosurg reactions to anti-inflam
Psychiatry 1988;51:731-2.

2 Redmond AD. Drskinesia induced by mefanamic acid. $7 R$ Soc Med 1981;74:558-9.

3 Cremona-Barbaro A. Extrapyramidal symptoms following mefanamic acid. $\mathcal{F} R$ Soc Med 1983;76:435.

+ Sandyk R, Gillman MA. Acute exacerhation of Parkinson's disease with sulindac. Ann Neurol 1985;17:104-5.

5 Anderson CB, Larson EJ. Diflunisal in idiopathic Parkinson's disease. Neurologv 1984;34:400.

6 L.eenders KL, Palmer AJ, Quinn N, et al. Brain dopamine metabolism in patients with Parkinson's disease measured with positron emission tomographs. I Neurol Neurosurg Pswchiatr 1986;49:853-60

\section{Gynaecomastia induced by angiotensin converting enzyme inhibitor}

Drs Yuji Nakamura, Keiko Yoshimoto, and Shigeki Saima (Department of Internal Medicine, National Medical Centre Hospital, Tokyo, Japan) write: Gynaecomastia may be induced or aggravated by a variety of drugs. We report a case of breast enlargement secondary to the administration of angiotensin converting enzyme inhibitor.

A 72 year old man with mild essential hypertension had been receiving captopril $75 \mathrm{mg}$ a day since October 1987. He had never suffered from liver disease, diabetes mellitus, or alcoholism and had not taken any kind of drug. Four months later he noticed a painful gynaecomastia (the size of an egg) on the left side. No urological abnormalities were found. Liver function and renal function were normal, and serum concentrations of triiodothyronine, thyroxine, thyroid stimulating hormone, prolactin, and oestradiol and 24 hour urinary excretion of 17-ketosteroid and 17-hydroxycorticosteroid were all within the normal range. In May 1989 captopril was stopped and nifedipine $30 \mathrm{mg}$ a day was started. One month later the breast enlargement and mamillary pain vanished, but he complained of flushing and foot oedema. Enalapril $5 \mathrm{mg}$ a day was given once a day, but he complained of painful gynaecomastia again within two weeks and refused to take this drug. We changed the antihypertensive drug to prazosin $2 \mathrm{mg}$ a day in August 1989, and gynaecomastia disappeared thereafter.

Markkusse and Meyboom first reported gynaecomastia associated with the use of captopril and suggested that gynaecomastia might be induced by drugs containing sulphydryl. Our patient had breast enlargement while receiving not only captopril but also enalapril, which does not contain the sulphydryl group. Therefore we suggest that angiotensin converting enzyme inhibitor itself induced gynaecomastia.

1 Markkusse HM, Meyboom RHB. Gynaccomastia associated with captopril. Br.Med f 1988;296:1262.

\section{Severe magnesium toxicity after magnesium sulphate enema in a chronically constipated child}

Drs M R Ashton, D Sutton, and M Nielsen (Princess Anne Hospital, Southampton SO9 4HA) write: The dangers of iatrogenic magnesium toxicity have been recognised in adults in the management of hepatic coma (rectally administered), ${ }^{12}$ pre-eclampsia (intravenously administered),,$^{34}$ and self poisoning (used as a cathartic). ${ }^{5}$ The use of magnesium sulphate enemas in managing hyaline membrane disease in premature infants was discontinued after reports of magnesium induced cardiorespiratory arrest. ${ }^{\circ}$ Eleven years ago Brown and Campbell reported a near fatal case of magnesium toxicity after administration of a magnesium sulphate enema to a chronically constipated child. We report a second such case.

A 25 month old girl with a long history of constipation, treated with lactulose, senna, suppositories, and weekly enemas, presented to the casualty department about one hour after the district nurse had administered what was thought to be a soap and water enema. She was atonic and areflexic, with shallow respirations. Her pupils reacted to light, her blood pressure was $150 / 60 \mathrm{~mm}$ $\mathrm{Hg}$, and her pulse 80 beats/min. Over five minutes her pupils became fixed and dilated and she became apnoeic. There were no doll's eyes or corneal reflexes, though her fundi were normal. She was intubated (with no gag reflex noted) and ventilated. A presumptive diagnosis of raised intracranial pressure was made and $100 \mathrm{ml}$ of $20 \%$ mannitol was given before computed tomography of the brain. The scan was normal. The child was transferred to the intensive care unit for continued support.

The district nurse had meanwhile been contacted and said that half a Fletcher's magnesium sulphate enema (about $32.5 \mathrm{~g}$ magnesium sulphate) had been given and retained. Acute magnesium toxicity was diagnosed and confirmed by analysis of a blood sample taken on arrival; magnesium $7 \cdot 1 \mathrm{mmol} / \mathrm{l}$ (normal $0.70-0.95 \mathrm{mmol} / \mathrm{l}$ ) calcium $3.1 \mathrm{mmol} / \mathrm{l}$. The sample also showed hypokalaemia $(1.8 \mathrm{mmol} /$ 1). An electrocardiogram showed the changes typical of magnesium toxicity - a prolonged PR interval and QRS widening. Electrical stimulation of the ulnar nerve produced no twitches of the forearm muscles, confirming complete neuromuscular blockade.

A forced calcium diuresis was not used in view of her hypokalaemia, the absence of cardiovascular compromise, the previous administration of mannitol, and her rapidly improving clinical state. As the mannitol induced diuresis was established, the child's conscious state steadily improved and her magnesium values fell (figure). Eleven hours after presentation she was extubated. Two days later she was discharged home, neurologically normal.

Urine was collected for 24 hours after admission

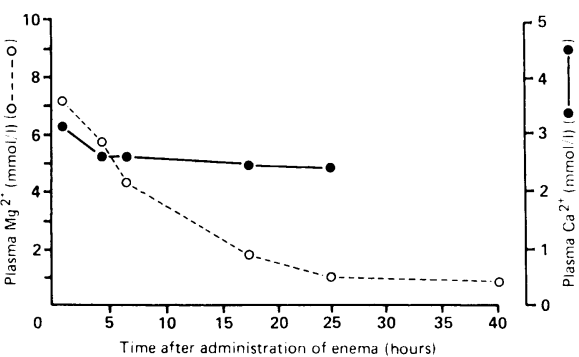

Plasma magnesium and calcium values during the first 40 hours

Analysis showed $33.2 \mathrm{mmol}$ magnesium in the 21.5 hours (normal 1.7-6.8 mmol $/ 24 \mathrm{~h}$ ), which was only $12.5 \%$ of the rectal dose given (about $4 \mathrm{~g}$ of the $32.5 \mathrm{~g}$ load). Probably not all of the rectal dose was retained and not all of it absorbed.

Magnesium is usually absorbed in the smal bowel, but the intact rectum and colon can absorb considerable quantities. ${ }^{\triangleright}$ In adult cases of magnesium poisoning, magnesium was generally administered over a long period. In both our case and that previously reported ${ }^{7}$ a single large dose of magnesium was given $(32.5 \mathrm{~g}$ and $65 \mathrm{~g}$ respectively). Both children were chronically constipated, and chronically dilated rectum and colon probably provided a greater surface area for absorption.

The mechanisms for regulating magnesium concentrations are efficient, with the kidney acting as the main homoeostatic organ under parathyroid hormone control. Physiologically, calcium and magnesium can be regarded as antagonists. This fact, together with the rapid urinary excretion of excess magnesium and the concurrent fall in plasma calcium concentration that should occur in hypermagnesaemia, has led to the use of forced calcium diuresis in managing magnesium poisoning. In our case the mannitol provided the diuresis, and the calcium value was never depressed-an unusual, though previously reported, phenomenon.'

The neurological action of magnesium is complex and thought to entail both presynaptic and postsynaptic blockade of the neuromuscular junction. In our case, as well as neuromuscular blockade, central effects appeared to be present, with abolition of brain stem reflexes, the recovery of which correlated with the fall in magnesium values.

We question whether the administration of magnesium sulphate enemas to chronically constipated children is ever justified. They should certainly be avoided in children with renal insufficiency or Hirschsprung's disease. When enemas are to be given in the community the type should be specifically prescribed and carefully checked (the packaging of Fletcher's phosphate and of magnesium enemas is very similar). Children should be observed for 30-60 minutes after the enema has been administered.

We thank Professor I C S Normand and Mr J Atwell for their help in preparing this report.

1 Collinson PO, Burroughs AK. Severe hypermagnesaemia due to magnesium sulphate enemas in patients with hepatic coma. magnesium sulphate enemas in patients with hepatic

2 Morton AR, Bailie GR. Severe hypermagnesaemia after magnesium sulphate enemas. Br Med f 1985;291:516.

3 Richards A, Stather-Dunn L, Moodley J. Cardiopulmonar arrest after the administration of magnesium sulphate. $S$ Af Med f 1985;67:145

4 McCubbin JH, Sibai BM, Abdella TN, Anderson GD. Cardiopulmonary arrest due to acute maternal hypermagnesaemia Lancet 1981;i:1058.

5 Jones J, Heiselman DO, Dougherty J, Eddy A. Cathartic induced magnesium toxicity during overdose management. Ann Emerg Med 1986;15:1214-8.

6 Outerbridge EW, Papgeorgiou A, Stern L. Magnesium sulfate enema in a newborn. Fatal systemic magnesium absorption. FAMA 1973;224:1392-3.

Brown AT Campbell WAB. Hazards of hypertonic magnesium enema therapy. Arch Dis Child 1978;53:920.

8 Stevens AR, Wolff HG. Magnesium intoxication. Absorption from the intact gastrointestinal tract. Arch Neurol Psychiutry 1950;63:749-59. 